\title{
Valuation of Wind Energy Turbines Using Volatility of Wind and Price
}

\author{
Doron Greenberg', Michael Byalsky² \& Asher Yahalom ${ }^{3,4}$
}

1 Department of Economics \& Business Administration, Ariel University, Ariel, Israel, dorongre@ariel.ac.il

2 Department of Economics, the Hebrew University of Jerusalem, Jerusalem, Israel, michael.byalsky@mail.huji.ac.il

3 Department of Electrical \& Electronics Engineering, Ariel University, Ariel, Israel, E-mail: asya@ariel.ac.il

4 Princeton University, Princeton, New Jersey 08543, USA

* Correspondence: asya@ariel.ac.il

\begin{abstract}
The limitedness of the nonrenewable local energy resources in Israel, even in background of the later gas fields' findings, continues to force the state to devote various efforts for the 'green' energy development. These efforts include installations both in the solar and in the wind energy, with a purpose to improve the diversity of energy sources. While the standard discounted cash flow (DCF) method using the net present value (NPV) criterion is extensively adopted to evaluate investments, the standard DCF method is inappropriate for the rapidly changing investment climate and for the managerial flexibility in investment decisions. In recent years, the real options analysis (ROA) technique is widely applied in many studies for valuation of renewable energy investment projects. Hence, we apply in this study the real options analysis approach for the valuation of wind energy turbines and apply it to the analysis of wind energy economic potential in Israel.
\end{abstract}

Keywords: Wind energy; Renewable resources; Black-Scholes model

\section{Introduction}

(A) The Raising Role of Wind Energy in the World

EVEN during prolonging global economic crisis, the worldwide wind power ascent continues. The world's wind power capacity according to the Global Wind Energy Council (GWEC) report, added in $201039.1 \mathrm{GW}$, growing by 24\% during the year, $40.6 \mathrm{GW}$ in 2011, growing by $20.5 \%$ per year, and $44.8 \mathrm{GW}$ in 2012 (18.8\% growth during the year: $78 \%$ growth in the last three years). Thus, the total installations at the end of 2012 provide up to $282.6 \mathrm{GW}$. A huge part of this power was produced in China - $1^{\text {st }}$ place globally, with $75.3 \mathrm{GW}$, or $26.7 \%$ of the world product (about $30 \%$ of the world year's additions) and USA $-60.0 \mathrm{GW}$, or $21.2 \%$ of the world product, while Germany, Spain, and India ( $3^{\text {rd }-5} 5^{\text {th }}$ places) produced $25.7 \%$ together [1].

Wind energy is now a significant participant in the world's energy market. The 2012 global wind power market grew by more than $10 \%$ compared to 2011, representing investments of about 56 billion $€$. The main markets of the wind energy are situated in Asia, North America, and Europe, each of which installs 13-15 GW of new capacity each year. About half a million people are now employed, corresponding to the European Wind Energy Association (EWEA) publication, by the wind industry around the world [2]. 


\section{(B) Current Wind Energy Installations in Israel}

Considering the growing Israeli energy market, even nowadays, when plentiful sources of traditional nonrenewable energy such as the vast gas fields, that were found in the Mediterranean Sea off the coast of Israel: Tamar (Tamar gas field [3]), and Leviathan (Leviathan gas field [4]), with the estimated quantity of 356 and 450 billion cubic meters respectively, the possibility of their exhaustion still forces the state, as other numerous political entities, to devote significant efforts to 'green' energy research and development. This is also important from the point of view of reducing carbon emission and global warming. These efforts are undertaken primarily in developing solar energy, but also recently in wind energy facilities. Yet the wind power amount produced in Israel is rather small compared to the continuously growing global market, however, the recent steps undertaken by the state are destined to make the situation better.

Israel currently operates a wind farm in Asanyia mountain in the Golan Heights, with an installed capacity of $6 \mathrm{MW}$ (10 turbines reaching a height 50 meters (blades included), each with a power capacity of $600 \mathrm{~kW}$ ), this is a typical consumption of about five thousand families. The duty cycle of the wind farm reaches $97 \%$, and electricity production is worth 1 million US $\$$ a year. Indeed, the wind energy potential of Israel is rather restricted due to moderate- or poor-wind velocities' in most areas and the restricted amount of areas with high average wind speed. In many areas worth of wind energy development, one is encountered by opposition of green groups on landscape conservation grounds and the influence of the facility on local and migrating birds. Nevertheless, satisfying the Israel Ministry of Environmental Protection (IMEP) directions, the state of Israel continues efforts for the development of additional farms with a $50 \mathrm{MW}$ capacity [5].

As it is emphasized in a document issued by the Israeli Parliament (Knesset), a better estimate, based on the wind turbines' technical development, gives a value of more than 500 MW for the Israeli potential wind energy potential capacity [6]. One of the perspective areas for the efficient wind technology development, considering its climatic characteristics, is the region of the Ariel city in Samaria [7], the current research, however, is devoted to another region [43].

\section{(C) The Current Research Goals}

The main purpose of this paper is to study the effect of energy value fluctuations on the assessment of the profitability of wind turbine facilities using the real option analysis method. The economic output of a wind turbine installation is a function of its electric energy output and the value of market energy. The electric energy output is a function of the turbine used and wind speed statistics. The turbine used can be chosen to have an optimal cut-in velocity (the wind speed level at which the turbine starts to generate electricity), and the cut-out velocity (the speed level at which the facility hits its alternator limit and stops to produce more power output following increases in a wind velocity) [8]. For a more technical discussion we refer the reader to results of our previous studies on wind power production, devoted to the technological appropriateness and environmental relevance issues $[7,9,10,11]$. While the total annual energy output of the turbine facility can be known to a high certainty, the market prices of energy may vary indeterminately, and thus should be considered as the most serious investment risk. To evaluate the financial risk correctly we suggest employing the real option analysis method which is the subject of the current study. In a wider sense, our manuscript contributes to the risk analysis of Grossman, that is the way a "decentralized economy allocates risk and investment resources when information is dispersed" [12, p. 773]. 


\section{Materials and Methods}

In this study we concentrated on the wind speed distribution at the golan heights area, using the information available from the meteorological service of the israel ministry of transport [13], gathered by the merom golan meteorological station, one of the 84 Israeli meteorological facilities which is situated at the relevant area [14], for the year 2014. The file used includes 52,066 data points gathered during the specified period. This includes sample values of the wind speed, one observation for every 10 minutes or 144 values per day (except some non-significant missing values) [15]. We describe the data analytically using the Weibull probability density function (PDF). This is commonly accepted as the most appropriate function describing the wind speed statistical frequencies at a given location in most world locations. This data is essential for planning of the wind turbine optimal choice [7].

The Weibull PDF is determined, in addition to a random variable $X$ representing here the wind speed, by two parameters which are location dependent. They are a shape parameter $\mathrm{k}$ (dimensionless) and a scale parameter $\lambda(\mathrm{m} / \mathrm{s}$ for the wind speed), which together determine the following PDF form:

$$
f(x ; \lambda, k)=\left\{\begin{array}{ll}
\frac{k}{\lambda}\left(\frac{x}{\lambda}\right)^{k-1} e^{-\left(\frac{x}{\lambda}\right)^{k}}, & x \geq 0 \\
0, & x=0
\end{array} .\right.
$$

Both PDF parameters are important for choosing the best location for the appropriate wind turbine, which imply the wind farm economical value [16].

While the generic discounted cash flow (DCF) approach using the net present value (NPV) criterion is generally adopted to evaluate investments, the DCF method is inappropriate for a rapidly changing investment situation (Dixit and Pindyck [20]; Herath and Park [21]; Lee and Shih [22]) and does not take into account managerial flexibility in investment decisions (Hayes and Abernathy [23]; Hayes and Garvin 24]; Trigeorgis and Mason [25]; Trigeorgis [26]). In the current study we consider a two-stage approach - one turbine at the $1^{\text {st }}$ stage and a field of 50 at the $2^{\text {nd }}$ stage; along with the possibility to withdraw at the $2^{\text {nd }}$ stage. Hence the scenario is a one in which managerial flexibility can be practiced.

Currently, the real option analysis method is widely applied in many studies for valuation of renewable energy investment projects, for example Lee and Shih [18], Kumbaroğlu, Madlener and Demirel [27], Boomsma, Meade and Fleten [28], Menegaki [29]. We thus apply in this paper the real options analysis method for evaluation of the economic value of wind energy turbines in a specific location. In particular, we analyze the value of the investment opportunities which add value to the investment due to managerial flexibility. It is worth mentioning that the option valuation method has become more sophisticated by using approaches such as the binomial lattice, the mean reverting jump-diffusion method, and stochastic volatility model. It is also used for other types of hazards such as technological risks (Deng [30], Menegaki [29], Siddiqui, Marnay, and Wiser [31], Davis and Owens [32], Baringo and Conejo [33]).

However, we have decided to adopt the basic Black-Scholes equation of a financial market [34] because we focus on the underestimated value of the option to abort the investment in an environment where it is not possible to foresee the standard deviation using numerical tools.

In this study we analyze the possibility of installing additional turbines in the Asanyia mountain in the Golan Heights, in order to extract profit from wind generated power. We have partly based our study on the known results of the wind turbines construction and use in Israel [35], while part of the numbers presented here are rather rough estimates. The decision to construct a field which is a collection of many turbines can be divided into two stages: in the $1^{\text {st }}$ stage we build one unit. After building and operating this single unit for few years and gaining confidence in the technical and financial output, the $2^{\text {nd }}$ stage 
regarding the decision of building the entire turbine field is made, based on electricity price at this stage as well as the future predicted energy evaluation.

We evaluate the uncertainty over future electricity market price as an economic value of an underlying asset of a real option using the Black-Scholes equation [34]:

$$
C=S_{0} N\left(d_{1}\right)-K e^{-r T} N\left(d_{2}\right),
$$

where

$$
\begin{aligned}
& d_{1}=\frac{\ln \left(S_{0} / K\right)+\left(r+\sigma^{2} / 2\right) T}{\sigma \sqrt{T}}, \\
& d_{2}=\frac{\ln \left(S_{0} / K\right)+\left(r-\sigma^{2} / 2\right) T}{\sigma \sqrt{T}}=d_{1}-\sigma \sqrt{T} .
\end{aligned}
$$

We use the following notations: $C$ is the call option value, $S_{0}$ is the market price of the underlying asset, $K$ is the exercise price, $r$ is the annual risk-free return, $T$ is the duration of the period (the number of years) till exercising the real option (constructing the entire turbine field), and $\sigma$ is the annualized standard deviation (StD) of the return of the underlying asset. $N$ is the symbol of the Gaussian cumulative probability density function (CDF).

\section{Results}

\subsection{Wind Energy Statistics}

Several various methods exist for fitting the observed data of the given location [17] to the PDF. We used the method of the maximum likelihood estimators for PDF fitting [18]. The corresponding Weibull PDF for the wind speeds distribution at the Merom Golan site, together with their distribution histogram, is shown below at Fig. 1.

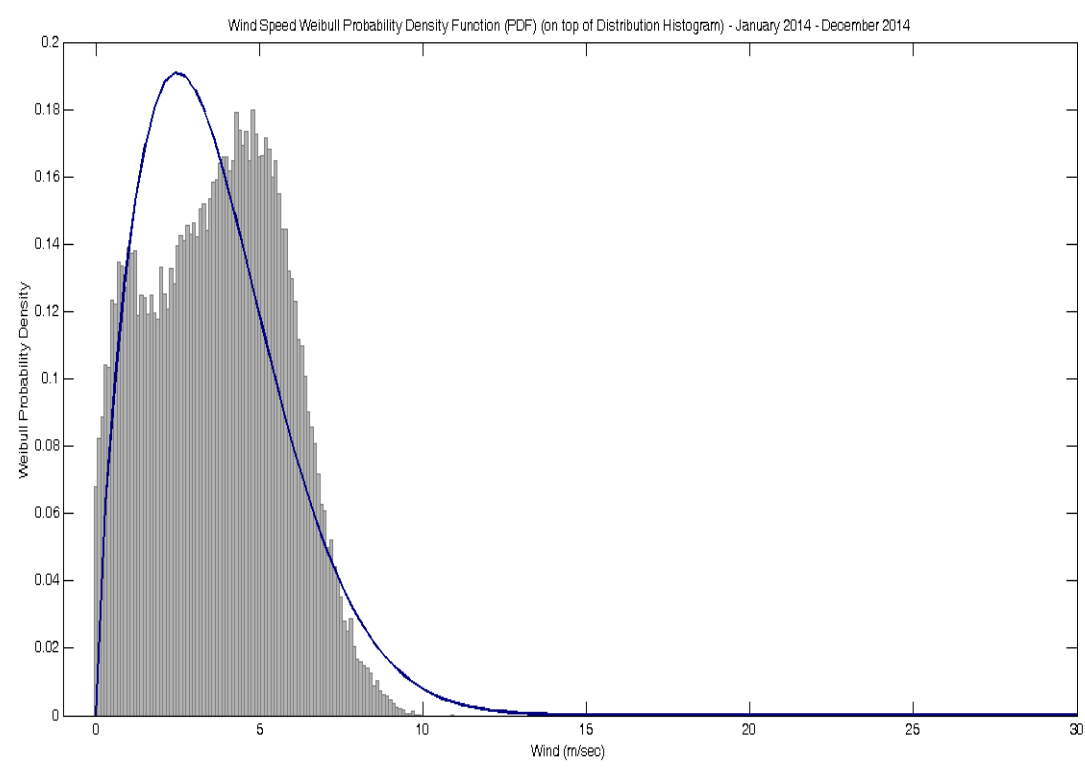

Fig. 1. The Weibull PDF diagram for the Merom Golan wind speeds distribution (on top of distribution histogram).

The figure demonstrates visually that low and moderate winds are widespread, with a tight condensation at the primary segment, which means that storms are just rare. It should be noticed that the distribution approximation by a Weibull PDF in this case is not perfect, though we could nevertheless obtain approximately based on it, the wind principal statistical parameters.

Estimated annual parameters of the wind Weibull distribution were found to be: $k$ $=1.7228$ and $\lambda=4.1206 \mathrm{~m} / \mathrm{s}$. In addition, we calculated (excess) kurtosis (a measure of the 
PDF sharpness) to be 2.1757, and skewness (a measure of the PDF asymmetry) as 0.0574, were calculated to demonstrate the specific type of the Weibull PDF.

The main meaningful statistical parameter for planning of the wind turbine installation, the speed mean, was obtained of $3.73 \mathrm{~m} / \mathrm{s}$, with Standard deviation of 2.03, during the given period, with a positive right-skewed tail. This finding, in accordance with the Israeli Cooperative for Renewable Energy conclusions [19], indicates the possibility of wind energy exploitation in the investigated region.

\subsection{Economical Model}

All the used figures were elaborated in accordance with a proposed scenario as in a Table 1 below, where the real figures can be introduced according to the data of each project (all prices are given in millions \$US):

\begin{tabular}{|c|c|}
\hline \multicolumn{2}{|l|}{ Data for the Black-Scholes Option Value } \\
\hline Cost of the $1^{\text {st }}$ stage's one turbine building & 50 \\
\hline Annual turbine's profit in the $2^{\text {nd }}$ stage & 0.2 \\
\hline Present value of 50 turbines' profit over 20 years $=$ Stock Price now $\left(S_{0}\right)$ & 114.7 \\
\hline Cost of the $2^{\text {nd }}$ stage's for each turbine construction & 1.2 \\
\hline Number of turbines in the $2^{\text {nd }}$ stage (entire field) & 50 \\
\hline Cost of the $2^{\text {nd }}$ stage's 50 turbines building $=$ Exercise Price of Option $(\mathrm{K})$ & 60 \\
\hline Number of Periods to Exercise in years (T) & 2 \\
\hline Compounded Risk-Free Interest Rate ( $r$ ) & 0.02 \\
\hline Standard Deviation of prices of energy or electricity (annualized $\sigma$ ) & 0.031 \\
\hline
\end{tabular}

Table 1. Input data for the Black-Scholes option value calculation.

We apply here the technique of real option valuation as illustrated in Brealey et al. [36, p. 584], where we have replaced:

- The Stock Price with the current value of the field, $S_{0}=114.7$ million $\$ U S$, which is the present value of 20 years future operation with annual profit of 0.2 million \$US per turbine for a field of 50 turbines, discounted with $6 \%$ annual cost of capital;

- The Number of Periods to Exercise in years $(\mathrm{T})$ with the number of years between confirmation of $1^{\text {st }}$ stage (one unit) to the decision on the $2^{\text {nd }}$ stage (the field).

We have therefore calculated at first the call value, based on the annual StD estimation of 0.031, as 57.05 million \$US. This StD estimation of 0.031 is based on the data of the Electric Power Monthly report of the U.S. Energy Information Administration (EIA), Table 5.3 "Average Retail Price of Electricity to Ultimate Customers" [37]. 
Our assumption of the $1^{\text {st }}$ unit's building cost is equaled, as above mentioned, to 50 million \$US, where such high expenses of the first turbine's launching include, among others, research and development to adapt the turbine to the specific area under consideration and the cost of connecting it to the power grid, subtracted by the profit from operation.

We stress that the current work is based on assumed values and in this sense it is an exercise in applying the real option technique. Future work will depend on a more realistic estimation of both the investment costs in infrastructure and current energy prices.

Hence, the results indicate that the investment in the $1^{\text {st }}$ turbine stage is warranted, and that there is the option to follow-on adds significant value to the investment. It follows that the net profit of the $1^{\text {st }}$ stage is 57.05-50=7.05 million \$US for the standard deviation value of 0.031 , accordingly to the following data of a Table 2 (in a column for the case of $\mathrm{StD}=0.031$, which includes the intermediate values and the option to follow-on:

\begin{tabular}{|c|c|c|}
\hline \multicolumn{3}{|c|}{ Intermediate and Output Data } \\
\hline StD & 0.031 & 0.40 \\
\hline$\sigma \sqrt{T}$ & 0.0438 & 0.5657 \\
\hline$d 1$ & 15.7146 & 1.4990 \\
\hline$d 2$ & 15.6707 & 0.9333 \\
\hline Delta N(d1) Normal CDF & 0.5123 & 0.9331 \\
\hline $\begin{array}{l}\text { Value of the Call Option } \\
\text { to Follow-On }\end{array}$ & 57.05 & 59.48 \\
\hline
\end{tabular}

Table 2. Intermediate and output data for the Black-Scholes option value.

For comparison with a scenario lacking an option to abandon, the project value is estimated as the present discounted value of a difference between (i.e. the earnings from) the future cash flow raised from the $2^{\text {nd }}$ stage realization subtracted by the $2^{\text {nd }}$ stage building cost, which subtracted additionally by the $1^{\text {st }}$ stage building cost.

Applying to our numerical example, this yields just the negative benefit, meaning merely loss, of the

$(114.7-60) / 1.06^{2}-50=-1.3$ million \$US.

However, using StD of 0.031 yields a profit of 7.05 million \$US, as was calculated above. This is so because one can make a choice to abandon the project in its midst. This is the economic meaning of the real option.

\section{Discussion}

It is difficult to determine the direction and intensity of energy prices in the future. For example, the U.S. Energy Information Administration in its "Independent Statistics \& Analysis" publication "The Availability and Price of Petroleum and Petroleum Products Produced in Countries other than Iran" on May - June 2015 Update states the following: 
"The uncertainty on both the supply and demand side of the market could result in large future price movements [underlined by the authors]. The possible lifting of sanctions on Iran could move additional supply on to the world market and reduce prices, while an unexpected supply disruption at a time of low surplus production capacity may push prices higher. Meanwhile, if a slowdown in global economic activity from current levels occurred, it would reduce demand and result in higher-than-expected inventory builds, moving prices lower" [38]. This can be seen from the graph from the same source at Fig. 2, where the spread between production and consumption is widening since July 2014.

In addition to the world energy price uncertainty, in Israel there are at least four other sources for price uncertainty: (a) the possibility of military conflict; (b) the discovery of gas in Israel's shore; (c) the adoption of gas by the industry; For example, Foenicia - a glass manufacturer that was recently close to bankruptcy due to luck of gas turned to be a profitable [39]; and (d) the discovery of oil in the Golan Heights [40].

While it is still difficult with all these sources of uncertainty to determine the direction and intensity of the change of energy price, we must consider thus the possibility of high volatility in price. To this end, we will consider hereafter the possibility of high volatility taken to be $\mathrm{StD}=40 \%$ per annum.

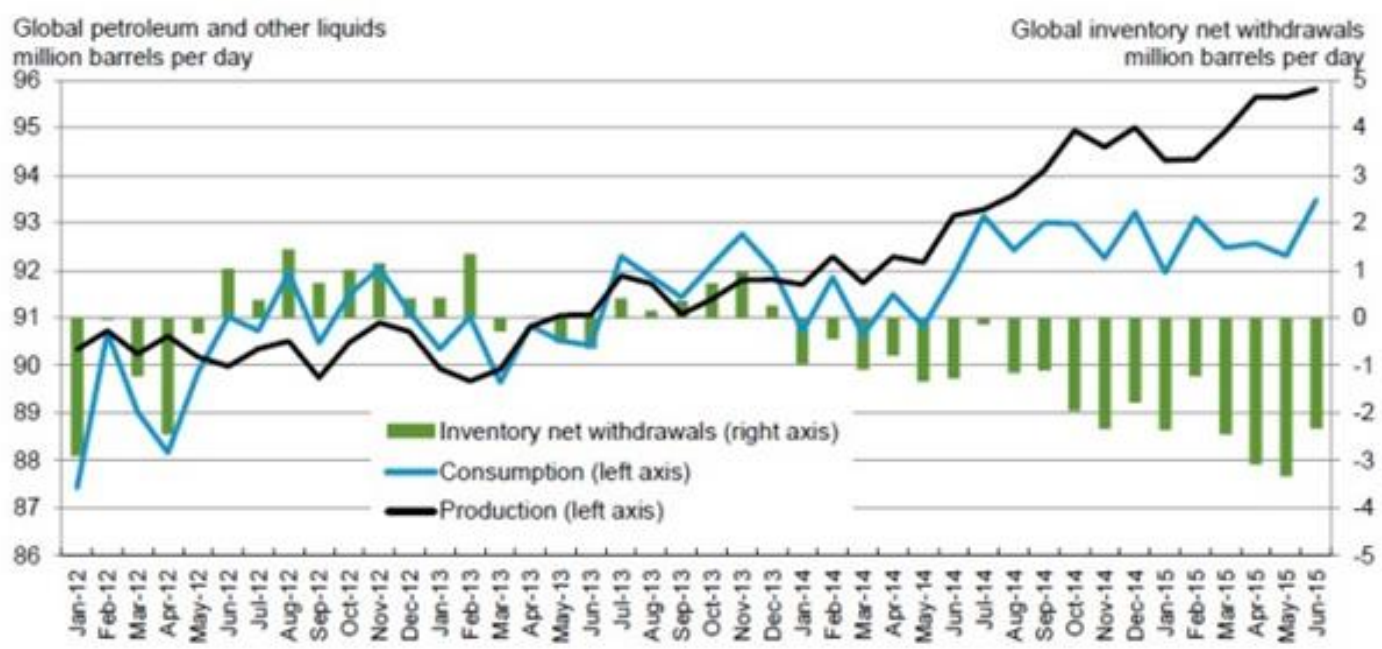

Fig. 2. Global Petroleum and other Liquids Production, Consumption and Inventory Net Withdrawals, January 2012-June 2015 [31].

Calculating the call value, based on the annual StD estimation of 0.4 , yields 59.48 million \$US (compared to 57.05 million \$US based on StD of 0.031). It follows that the net profit of the $1^{\text {st }}$ stage increased to 59.48-50 $=9.48$ million $\$$ US (see Table 2, a column for the case of $\mathrm{StD}=0.40$ ). It would be worth notice here that the main statistical parameters of the wind speed at the Merom Golan area, the mean and StD, are observed with a tendency to stability, without any significant divergence over the period of last years 2009-2014, as it follows from the calculated at Table 3 data:

\begin{tabular}{|l|l|l|l|l|l|l|}
\hline Year & 2009 & 2010 & 2011 & 2012 & 2013 & 2014 \\
\hline Speed mean $(\mathrm{m} / \mathrm{s})$ & 3.89 & 3.69 & 3.63 & 3.70 & 3.80 & 3.62 \\
\hline StD $(\mathrm{m} / \mathrm{s})$ & 2.10 & 2.12 & 2.00 & 2.03 & 2.05 & 1.99 \\
\hline Number of Samples & 2919 & 2920 & 2920 & 9774 & 2896 & 2898 \\
\hline
\end{tabular}




\begin{tabular}{|l|l|l|l|l|l|l|}
\hline $\mathrm{StD} / \sqrt{\boldsymbol{n}}(\mathrm{m} / \mathrm{s})$ & 0.039 & 0.039 & 0.037 & 0.021 & 0.038 & 0.037 \\
\hline
\end{tabular}

Table 3. Wind speed mean and StD at Merom Golan for the last period.

The expectation value of an annual average is the same as the expectation value for one sample but the standard deviation of the annual average is equal to the standard deviation of one sample divided by the square root of the annual number of samples (see Appendix A for a mathematical justification). Thus the standard deviation of the annual average of wind speed is between $0.6 \%-1.1 \%$ and can be further reduced by more sampling. A six year average based on 24327 samples will be $3.72 \mathrm{~m} / \mathrm{s}$ with only $0.4 \%$ standard deviation. The power curves of available turbines are described in [41] from which three examples are analyzed in this paper and are depicted in Fig. 3. The wind speeds described in Table 3 are for a height of ten meters for different heights we apply the velocity to height connection [42]:

$v(h)=v_{10}\left(\frac{h}{10}\right)^{a}$

in which $v(h)$ is the velocity at height $h, v_{10}$ is the velocity at a height of 10 meters and a is Hellmann's exponent which for a neutral air above human inhabited areas is about 0.34 . Among the turbines analyzed the largest is Enercon's model E101/3000 turbine with a radius of 50.5 meters. Hence we will assume from now on that the hub of the turbine is 60 meters. Table 4 will summarize the area and radii of the turbines under study:

\begin{tabular}{|l|l|l|l|}
\hline Turbine & $\begin{array}{l}\text { Enercon's } \\
\text { E101/3000 }\end{array}$ & $\begin{array}{l}\text { AWE's } \\
54-900\end{array}$ & $\begin{array}{l}\text { EWT's Directwind } \\
52 / 750\end{array}$ \\
\hline Area $\left(\mathrm{m}^{2}\right)$ & 8012 & 2290 & 2083 \\
\hline Radius $(\mathrm{m})$ & 50.5 & 27 & 25.75 \\
\hline
\end{tabular}

Table 4. Wind turbine geometric parameters

For this height we obtain a six year speed average of $6.84 \mathrm{~m} / \mathrm{s}$. The eleven year average of the power and standard deviation obtained for each turbine are depicted in Table 5, the total number of samples in this analysis is 31292 based on the wind data from Merom Golan. 


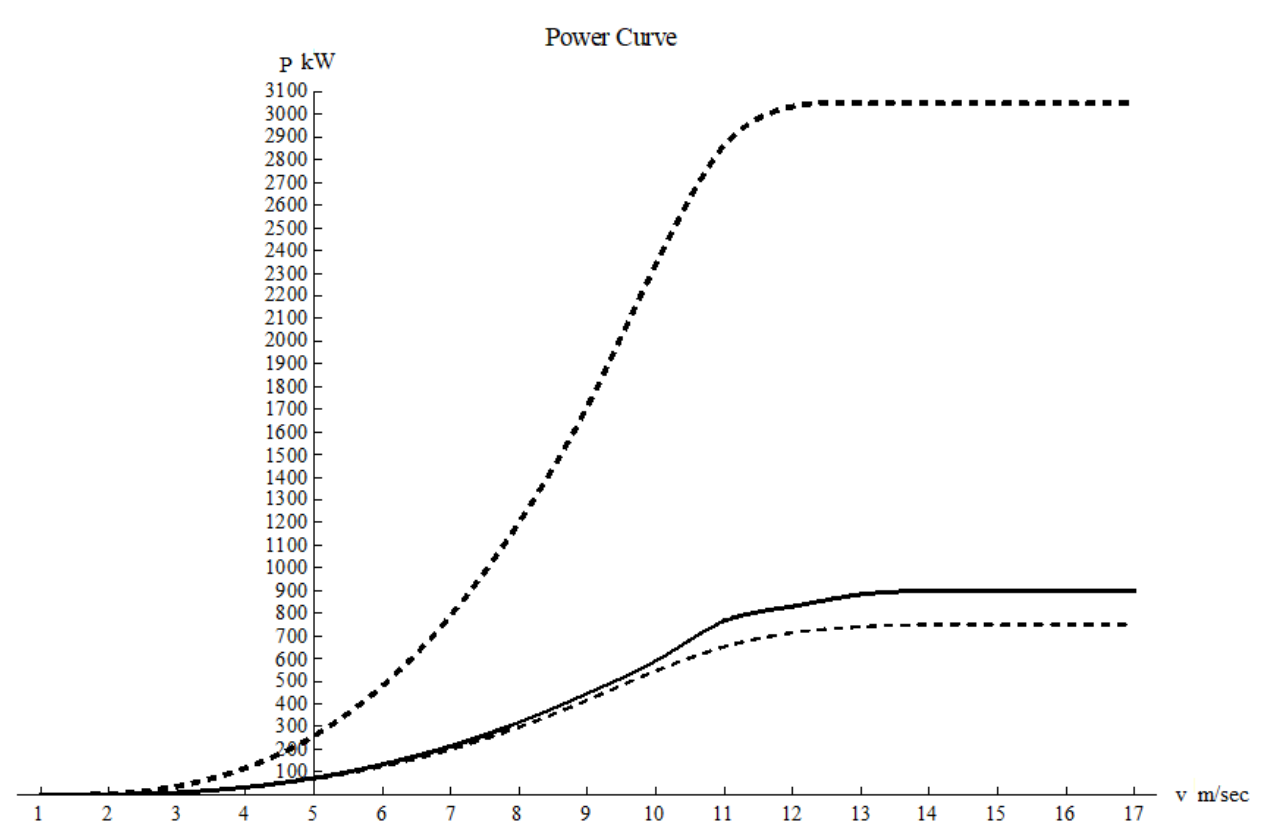

Fig. 3. Power curves of wind turbines [41]. The dashed thick curve is the power curve of Enercon's model E101/3000 turbine, the thick line is the power curve of AWE's model 54900 turbine and the dashed curve is the power curve of EWT's model Directwind 52/750 turbine.

\begin{tabular}{|l|l|l|l|}
\hline Turbine & $\begin{array}{l}\text { Enercon‘s } \\
\text { E101/3000 }\end{array}$ & $\begin{array}{l}\text { AWE's } \\
54-900\end{array}$ & $\begin{array}{l}\text { EWT's Directwind } \\
52 / 750\end{array}$ \\
\hline Average Power $(\mathrm{kW})$ & 1205.84 & 325.84 & 289.70 \\
\hline Power StD $(\mathrm{kW})$ & 1125.94 & 309.10 & 264.99 \\
\hline $\begin{array}{l}\text { Power StD/ } \sqrt{n} \\
(\mathrm{~kW})\end{array}$ & 6.36 & 1.75 & 1.50 \\
\hline$\%(\mathrm{StD} / \sqrt{n}) /$ Average & 0.52 & 0.54 & 0.52 \\
\hline Annual Revenue (SH) & $5,133,695$ & $1,387,218$ & $1,233,357$ \\
\hline Annual Revenue (\$) & $1,327,909$ & 358,825 & 319,027 \\
\hline
\end{tabular}

Table 5. Wind turbine power for eleven years of data acquisition

The standard deviation of average power for all turbines investigated is much lower than the standard deviations of energy price appearing in Table 2. Hence a long term project can ignore the risk connected with the standard deviation of wind speed. A formal proof for this decisive circumstance is given in Appendix B.

This circumstance determines the fact of non-relevancy of the speed variance, during prolonged period of time, for the wind turbine economic value; this should be compared to the significance of the energy prices for the turbine economic value.

Table 5 contains also the annual economic value of the turbine based on the current price of energy for consumers in Israel which is $0.486 \mathrm{SH}$ for $\mathrm{kW}$ hour on 11.9.15 the exchange rate for the same date is $3.866 \mathrm{SH}$ for one US \$. We assume that the turbine owner will need to pay for transmission and distribution hence the more conservative estimate of an annual profit of 0.2 million \$US per turbine quoted in the previous section. In practice the price is determined by governmental authorities who strike a balance between the interest 
of other producers, the cost of transmission and distribution and the public interest in clean energy.

\section{Conclusions}

Traditional calculation for an uncertain cash flow applies just the expected values of the cash flow from the project without the possibility to abandon. Given our empirical assumptions, this yields a loss of 1.3 million \$US instead of any profit, meaning the project becomes not worthwhile.

Nevertheless, applying the real option analysis, which reveals the value of the option to abandon the 2nd stage running as well, we turn the project just to become profitable and worthwhile. The value of the real option increases depending volatility to be either 57.05 million \$US or 59.50 million \$US depending on future volatility, and the profit is either 7.05 million \$US or 9.48 million \$US, respectively.

Finally, for Civil Engineering projects with volatility in input and mainly in output prices, it is important to consider the option to abandon the project from the beginning, as this option may turn the project to be profitable.

Author Contributions: Conceptualization, D.G. and A.Y.; methodology, D.G., M.B. and A.Y.; formal analysis, D.G., M.B. and A.Y.; writing-original draft preparation, D.G., M.B. and A.Y.; writing-review and editing, D.G., M.B. and A.Y.; All authors have read and agreed to the published version of the manuscript.

Funding: This research received no external funding

Institutional Review Board Statement: Not applicable

Informed Consent Statement: Not applicable

Conflicts of Interest: The authors declare no conflict of interest

\section{Appendix A}

Consider a random process $X(t)$, which is sampled at times $t_{i}$ each sample $X_{i}=X\left(t_{i}\right)$, is a random variable. We will assume that the process is stationary in the sense that each random variable has the same expectation value:

$E\left[X_{i}\right]=E\left[X_{j}\right]=\bar{X} \quad \forall i, j$.

and standard deviation:

$\sigma_{x_{i}}=\sigma_{x_{j}}=\sigma_{x} \quad \forall i, j$

We will also assume that the random variables are independent. Thus the covariance satisfies $C_{x_{i} x_{j}}=0, \forall i \neq j$. Let us now average $n$ samples as:

$X_{a}=\frac{1}{n} \sum_{i=1}^{n} X_{i}$

This implies that the expectation value of the average will be the same as that of the samples:

$E\left[X_{a}\right]=E\left[\frac{1}{n} \sum_{i=1}^{n} X_{i}\right]=\frac{1}{n} \sum_{i=1}^{n} E\left[X_{i}\right]=\frac{1}{n} \sum_{i=1}^{n} \bar{X}=\bar{X}$. 
(A.4)

However, the standard deviation of $X_{a}$ will be much smaller, since:

$\sigma_{X_{a}}^{2}=E\left[\left(X_{a}-\overline{X_{a}}\right)^{2}\right]=\frac{1}{n^{2}} E\left[\sum_{i, j}^{n}\left(X_{i}-\bar{X}_{l}\right)\left(X_{j}-\bar{X}_{J}\right)\right]=\frac{1}{n^{2}} \sum_{i, j}^{n} C_{x_{i} x_{j}}=\frac{1}{n^{2}} \sum_{i}^{n} C_{x_{i} x_{i}}=$ $\frac{1}{n^{2}} \sum_{i}^{n} \sigma_{X_{i}}^{2}=\frac{1}{n^{2}} \sum_{i}^{n} \sigma_{X}^{2}=\frac{\sigma_{X}^{2}}{n}$

Hence:

$\sigma_{X_{a}}=\frac{\sigma_{X}}{\sqrt{n}}$

And for a large amount of samples:

$\lim _{n \rightarrow \infty} \sigma_{X_{a}}=\lim _{n \rightarrow \infty} \frac{\sigma_{X}}{\sqrt{n}}=0$.

(A.7)

\section{Appendix B}

The revenue $R$ is the product of $E n$, the energy produced, and $C$, the price of energy. For a small amount of energy $d E n, d R$ is equal to:

$d R=C d E n$.

The gain $G$ is defined as the revenue per unit time:

$G=\frac{d R}{d t}=C \frac{d E n}{d t}=C P$,

in which $P=\frac{d E n}{d t}$ is the power. Thus the expectation of the gain is the correlation of the price and the power.

$E[G]=E[C P]=R_{C P}$.

Since the price is a random process which is largely independent of the power and is dependent among other things on the price of other energy source and administrative decisicions, we will assume that $C$ and $P$ are independent random variables, hence:

$E[G]=\bar{C} \cdot \bar{P}$,

in which $E[C]=\bar{C}$ is the average price and $E[P]=\bar{P}$ is the power average. The variance of the gain, as its standard deviation square, is thus:

$$
\sigma_{G}{ }^{2}=E\left[G^{2}\right]-\bar{G}^{2}=E\left[C^{2} P^{2}\right]-\bar{C}^{2} \bar{P}^{2}=E\left[C^{2}\right] E\left[P^{2}\right]-\bar{C}^{2} \bar{P}^{2}
$$


However, since

$E\left[C^{2}\right]={\sigma_{C}}^{2}+\bar{C}^{2}, E\left[P^{2}\right]={\sigma_{P}}^{2}+\bar{P}^{2}$,

it follows that:

$\sigma_{G}{ }^{2}=\left(\sigma_{C}{ }^{2}+\bar{C}^{2}\right)\left({\sigma_{P}}^{2}+\bar{P}^{2}\right)-\bar{C}^{2} \bar{P}^{2}={\sigma_{C}}^{2}{\sigma_{P}}^{2}+\bar{C}^{2}{\sigma_{P}}^{2}+\bar{P}^{2}{\sigma_{C}}^{2}$.

Hence:

$\frac{\sigma_{G}^{2}}{\bar{G}^{2}}=\frac{\sigma_{C}^{2}}{\bar{C}^{2}}+\frac{\sigma_{P}^{2}}{\bar{P}^{2}}\left(1+\frac{\sigma_{C}^{2}}{\bar{C}^{2}}\right)$.

Thus if $\frac{\sigma_{P}^{2}}{\bar{P}^{2}} \ll \frac{\sigma_{C}^{2}}{\bar{C}^{2}}$, and since necessarily $\frac{\sigma_{C}^{2}}{\bar{C}^{2}}<1$, we can write:

$\frac{\sigma_{G}^{2}}{\bar{G}^{2}} \cong \frac{\sigma_{C}^{2}}{\bar{C}^{2}}$.

However, notice that power fluctuations are not small, it is only the power average fluctuations over many samples that are small (see Appendix A), hence a more sophisticated approach is needed. We notice that the typical time for the change of power is much shorter than the typical time for the change of price. For example we can assume that price changes once a month while power is sampled every ten minutes. We define $\Delta T$ as a duration for which the price remains constant. Next we calculate the revenue for the total duration $T$ :

$$
R_{T}=\int_{0}^{R_{T}} d R=\int_{0}^{T} C P d t
$$

We now divide the duration $T$ to subduration of intervals $\Delta T$, and integrate $R$ as follows: $R_{T}=\sum_{n=1}^{N} \int_{T_{n-1}}^{T_{n}} C P d t$

In the above, $T_{n}-T_{n-1}=\Delta T$, and $T_{0}=0, T_{N}=T$. Since $C$ is constant for $\Delta T$ intervals we can write:

$R_{T}=\sum_{n=1}^{N} C_{n} \int_{T_{n-1}}^{T_{n}} P d t$.

Let us further divide the duration $\Delta T$ into subdurations $\Delta t=\frac{\Delta T}{M}$ in which $M$ is a large enough number; we may now write:

$\int_{T_{n-1}}^{T_{n}} P d t=\sum_{i=1}^{M} \int_{T_{n i-1}}^{T_{n i}} P d t$. 
In the above, $T_{n i}-T_{n i-1}=\Delta t$, and $T_{n 0}=T_{n-1}, T_{n M}=T_{n}$. If $M$ is large enough we may write approximately:

$\int_{T_{n-1}}^{T_{n}} P d t=\sum_{i=1}^{M} \Delta t P_{n i}=\frac{\Delta T}{M} \sum_{i=1}^{M} P_{n i}=\Delta T P_{n a}$.

where $P_{n a}$ is an average in the sense of (A.3), hence the fluctuations of $P_{n a}$ are small enough. The total revenue is therefore:

$R_{T}=\Delta T \sum_{n=1}^{N} C_{n} P_{n a}=\Delta T \sum_{n=1}^{N} G_{n a}$.

Thus the revenue is proportional to the sum of the average gains $G_{n a}$, which according to equation (B.7) have fluctuations which are a result of the dominant price fluctuations and the negligible power fluctuations.

\section{References}

1. "The global status of wind power in 2012," Global Wind Energy Council, Gwec.net. [Electronic version]. Retrieved September 15, 2013, from http://www.gwec.net/index.php?id=180.

2. "Global wind energy statistics," European Wind Energy Association. [Electronic version]. Retrieved September 16, 2013, from http://www.ewea.org/statistics/global-statistics/.

3. “Tamar gas field,” Wikipedia. Retrieved February 22, 2015, from http://en.wikipedia.org/wiki/Tamar_gas_field.

4. “Leviathan gas field," Wikipedia. Retrieved February 22, 2015, from http://en.wikipedia.org/wiki/ Leviathan_gas_field.

5. "Renewable energy," Israel Ministry of Environmental Protection. [Electronic version]. Retrieved July 31, 2009, from http://www.sviva.gov.il.

6. O. Lotan, "Wind energy power generation," Background paper, 21.09 .05 (in Hebrew). Jerusalem: Knesset, Research and Information Center, 2005.

7. M. Byalsky and A. Yahalom, "Modeling of the Wind Energy Use Efficiency", The $4^{\text {th }}$ Annual International Conference on Qualitative and Quantitative Economics Research (QQE 2014), GSTF, Phuket, Thailand, 28-29 ${ }^{\text {th }}$ Apr. 2014.

8. P. Gray and L. Johnson (1985). Wind Energy System. Upper Saddle River, NJ: Prentice Hall, 1985.

9. Y. Ditkovich, A. Kuperman, A. Yahalom, and M. Byalsky, "A Generalized Approach to Estimating Capacity Factor of Fixed Speed Wind Turbines", IEEE Transactions on Sustainable Energy (2012), Vol. 3 (3), pp. 607-608, doi:10.1109/TSTE.2012.2187126.

10. Y. Ditkovich, A. Kuperman, A. Yahalom, and M. Byalsky, "Site-Dependent Wind Turbine Performance Index", International Journal of Renewable Energy Research (2013), Vol. 3 (3), pp. 592-594.

11. Y. Ditkovich, A. Kuperman, A. Yahalom, and M. Byalsky, "Alternative Approach to Wind Turbine Performance Index Assessment”, Journal of Energy Engineering (2014), Vol. 140 (4), 06014001, pp. 1-4.

12. S.J. Grossman, "Dynamic Asset Allocation and the Informational Efficiency of Markets", The Journal of Finance (1995), Vol. 50 (3), pp. $773-787$.

13. “The Israel Meteorological Service Site”. Retrieved May 26, 2015, from http://www.ims.gov.il/ims/all_tahazit/.

14. “The Israel Meteorological Stations' Characteristics". Retrieved June 1, 2015, from https://data.gov.il/sites/data.gov.il/files/metadata10minutesIMS7.XLSX.

15. "The Government Information Data Bases' Site". Retrieved June 3, 2015, from https://data.gov.il/ims/7.

16. "Weibull statistics," Reliability Engineering. Retrieved December 30, 2013, from http://www.weibull.nl/weibullstatistics.htm. 
17. P. Bhattacharya and R. Bhattacharjee, "A study on Weibull distribution for estimating the parameters", Journal of Applied Quantitative Methods (2010), Vol. 5 (2), pp. 234-241.

18. “Weibull Parameter Estimates", MathWorks Documentation Center. [Electronic version]. Retrieved August 18, 2013, from www.mathworks.com/help/toolbox/stats/wblfit.html.

19. H. Levy, "Installation of small wind turbines for the electricity generation," Israeli Cooperative for Renewable Energy (in Hebrew). [Electronic version]. Retrieved December 30, 2013, from http://ecoop.org.il/index.php?option=com_content $\&$ view $=$ article $\& i d=88 \&$ Itemid $=135$.

20. A.K. Dixit and R.S. Pindyck, “The options approach to capital investment”, Harv. Bus. (1995), Rev. 73 (3), pp. 105-115.

21. H.S.B. Herath and C,S. Park, "Economic Analysis of R\&D projects: an options approach”, Eng. Econ. (1999), Vol. 44 (1), pp. $1-35$.

22. Shun-Chung Lee and Li-Hsing Shih, "Renewable energy policy evaluation using real option model — The case of Taiwan," Energy Economics (2010), Vol. 32, (S1), pp. 67-78.

23. R.H. Hayes and W.J. Abernathy, "Managing our way to economic decline”, Harv. Bus. (1980), Rev. 58 (4), pp. 67-77.

24. R.H. Hayes and D. Garvin, "Managing as it tomorrow mattered”, Harv. Bus. (1982), Rev. 60 (3), pp. 70-79.

25. L. Trigeorgis and S.P. Mason, "Valuing managerial flexibility and strategy in resource", Midl. Corp. Financ. J., (1987), Vol. 5 (1), pp. 14-21.

26. L. Trigeorgis, "Real Option: Managerial Flexibility and Strategy, Resource Allocation”, $2^{\text {nd }}$ ed., Parager Publisher, Westport, 1997.

27. G. Kumbaroğlu, R. Madlener, and M. Demirel, "A real options evaluation model for the diffusion prospects of new renewable power generation technologies", Energy Economics (2008), Vol. 30 (4), pp. 1882-1908.

28. T.K. Boomsma, N. Meade, and S.-E. Fleten, "Renewable energy investments under different support schemes: A real options approach", European Journal of Operational Research (2012), Vol. 220 (1), pp. 225-237.

29. Menegaki, "Valuation for renewable energy: a comparative review", Renewable and Sustainable Energy Reviews (2008), Vol. 12 (9), pp. 2422-2437.

30. S. Deng, "Stochastic models of energy commodity prices and their applications: Mean-reversion with jumps and spikes", The POWER working papers series, PWP-073. Berkeley: University of California Energy Institute, 2000.

31. A.S. Siddiqui, C. Marnay, R.H. Wiser, "Real options valuation of US federal renewable energy research, development, demonstration, and deployment”, Energy Policy (2007), Vol. 35 (1), pp. 265-279.

32. G.A. Davis, B. Owens, "Optimizing the level of renewable electric R\&D expenditures using real options analysis", Energy Policy (2003), Vol. 31 (15), pp. 1589-1608.

33. L. Baringo, A.J. Conejo, "Strategic Wind Power Investment," IEEE Transactions on Power Systems (2014), Vol.29.(3), pp.1250-1260.

34. F. Black and M. Scholes, "The pricing of options and corporate liabilities," The Journal of Political Economy (1973), Vol. 81 (3), pp. 637-654, 1973.

35. "Wind Energy Golan" [Electronic version]. Retrieved February 14, 2015, from http://www.wind-golan.com/.

36. R. A. Brealey, S. C. Myers, and F. Allen. "Principles of corporate finance," $10^{\text {th }}$ ed., New York: McGraw-Hill/Irwin, 2011.

37. "Electric Power Monthly Report of the U.S. Energy Information Administration (EIA)”, Electricity. Retrieved September 24, 2015 from http://www.eia.gov/electricity/?fm\&t=epmt_5_03.

38. 'The Availability and Price of Petroleum and Petroleum Products Produced in Countries Other Than Iran". No. 23 in a series of reports required by section 1245(d)(4)(A) of the National Defense Authorization Act for Fiscal Year 2012. Retrieved October 6, 2015 from http://www.eia.gov/analysis/requests/ndaa/pdf/ndaa.pdf.

39. "Finally: Phoenicia factory from Nazareth Illit is connected to the natural gas", Globes, February 3, 2015 (in Hebrew), from http://www.globes.co.il/news/article.aspx?did=1001006735. 
40. "Huge oil discovery on Golan Heights," Globes October 7, 2015, from http://www.globes.co.il/en/article-huge-oil-discovery-ongolan-heights-1001071698.

41. C. Carrillo, A.F. Obando Montaño, J. Cidrás, and E. Díaz-Dorado, "Review of power curve modelling for wind turbines" (2013), Renewable and Sustainable Energy Reviews, Vol. 21, pp. 572-581. http://grupo_ene.webs.uvigo.es/.

42. M. Kaltschmitt, W. Streicher, and A. Wiese, "Renewable energy: technology, economics, and environment",Springer, 2007, ISBN 3-540-70947-9, ISBN 978-3-540-70947-3, p. 55.

43. D. Greenberg, M. Byalsky \& A. Yahalom “On the Wind Turbines Assessment by Real Options Technique in Israel” Proceedings of BIONATURE 2016: The Seventh International Conference on Bioenvironment, Biodiversity and Renewable Energies, June 26 - 30, 2016, Lisbon, Portugal 